\title{
Immunocytochemistry of matrix proteins in calcified tissues: functional biochemistry on section
}

\author{
A. Nanci, R. Wazen, C. Nishio, S.F. Zalzal \\ Laboratory for the Study of Calcified Tissues and Biomaterials, Faculty of Dentistry, Université de \\ Montréal, Montreal, Canada
}

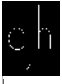

(C)2008 European Journal of Histochemistry

The organic matrix of calcified tissues comprises collagenous and/or noncollagenous matrix proteins (NCPs). Identification and precise mapping of these matrix components is essential for determining their function, formulating coherent hypotheses on their mechanism(s) of action, and developing novel therapeutic approaches based on biologics. Fibrillar collagen can be readily identified by its conspicuous structure, however, NCPS, in general, do not individually exhibit characteristic structural features that permit to identify them and morphologically determine their localization. To address this limitation, we have used immunocytochemistry, a form of "biochemistry on section", to correlate composition with structure. For cytochemical characterizations, including immunolabeling, our laboratory has opted for colloidal gold labelings and pioneered their application to calcified tissues because they yield high spatial resolution and are quantitative. Over the years, this approach has been applied to identify and map various NCPs in bone and teeth and, in this review of our work, we will emphasize some selected studies that highlight it application to also achieve functional information.

Key words: calcified tissues, colloidal gold, functional cytochemistry, noncollagenous proteins, animal models, tracer studies.

Correspondence: Antonio Nanci,

Laboratory for the Study of Calcified Tissues and Biomaterials, Faculty of Dentistry, Université of Montréal Montréal, Canada

Tel.: +1514.3435846.

Fax: +1514.3432233.

E-mail: antonio.nanci@umontreal.ca

Paper accepted on October 13, 2008

European Journal of Histochemistry

2008; vol. 52 issue 4 (October-December): 201-214

This paper was presented by Antonio Nanci at the XXXII National Congress of the Italian Society of Histochemistry, Messina, Italy, May 31 - June 2, 2007, as the Maffo Vialli Lecture, while receiving the Maffo Vialli International Award for Histochemistry.
7 here are essentially two versions of calcified tissues in the body; the collagen-based ones (bone, cartilage, dentin, cellular cementum) and noncollagenous ones (enamel, acellular cementum). Noncollagenous and collagenous calcified tissues exhibit common formation features, even though the final products are structurally distinct. Hence, any new information obtained in one calcified tissue will also have a more global impact on our understanding of biomineralization in general. Collagen-based calcified tissues are characterized by an organic matrix consisting mainly of a meshwork of type I collagen (type II for cartilage) among which are interposed various noncollagenous matrix proteins (NCPs). The main function of collagen is to act as a scaffold and repository for mineral crystals. In terms of bulk composition, NCPs are minor constituents yet they play very important roles in both cell and matrix events leading to the formation and structuring of calcified tissues. They become integrated among the mineralized collagen to impart cohesion to the tissue. Noncollagenous calcified tissues consist entirely of NCPs and scaffolding is provided by the structural organization of the mineral itself, rather than by organic matrix. This category is exemplified essentially by enamel; however, it is not the only calcified tissue without collagen. Mineralization of acellular afibrillar cementum occurs within a matrix consisting mainly of NCPs (Bosshardt et al. 1998). In invertebrates, the shell of mollusks is made up of laminae of calcium carbonate separated by organic material, containing acidic macromolecules among others (Weiner 1986; Albeck et al. 1996).

Over the past few years, there has been a shift in the perception of biological mineralization, from a physiological process highly dependent on sustained active promotion to one relying more on rate limiting activities. Essentially, once $\mathrm{CaPO}_{4}$ deposition is initiated, the crux is then to control the spontaneous precipitation of mineral ions from supersaturated 
tissue fluids and limit it to well-defined sites (Huq et al. 2005; Murshed et al. 2005; Wilt 2005). Formative cells achieve this by creating microenvironments which facilitate mineral ion handling and by secreting proteins that stabilize $\mathrm{Ca}$ and $\mathrm{PO}_{4}$ ions in body fluids and/or control their deposition onto a receptive extracellular matrix (ECM). Genome sequencing and gene mapping have shown that several of these proteins are located on the same chromosome and that there is synteny across several species (Huq et al. 2005). In mammals, these stabilizing proteins include (i) ameloblastin (AMBN), amelogenin (AMEL) and enamelin in enamel; (ii) bone sialoprotein (BSP), dentin sialophosphoprotein, dentin matrix acidic phosphoprotein-1, matrix extracellular phosphoglycoprotein and osteopontin $(O P N)$ in bone, dentin and to some extent in cementum, (iii) statherin, histatin and proline-rich proteins in saliva, and (iv) caseins in milk. Collectively, these stabilizing proteins are referred to as the secretory calcium-binding phosphoprotein gene cluster. All of them, with the exception of AMEL, are located on human chromosome $4 \mathrm{q}$ (14 in rat and 5 in mouse) (Huq et al. 2005). It has been proposed that these proteins derive from the duplication and diversification of an ancestral gene during evolution, that is from the $5^{\prime}$ region of SPARC-like1 which initially arose from osteonectin/SPARC duplication about 600 million years ago (Huq et al. 2005; Sire et al. 2005). Recently, two novel proteins produced by ameloblasts, APIN and Amelotin, have been identified and their genes are also located to the secretory calcium-binding phosphoprotein cluster. Based on their localization, it has been suggested that they play a role in mediating the adhesion of epithelia to mineralized surfaces (Moffatt et al. 2006; 2008).

The bone, cementum and dentin NCPs form the Small Integrin Binding Ligand N-linked Glycoprotein (SIBLING) family that share a number of biochemical properties and functions, despite an overall paucity in homology (Fisher et al. 2001). Virtually all are glycoproteins, some of which contain relatively large amounts of sialic acid. The best characterized sialoproteins are BSP and OPN; both contain mineral binding amino acid sequences, and the Arg-Gly-Asp (RGD) sequence, which gives them the capacity to bind to the integrin class of cell surface receptors.

Despite major advances in our knowledge, there are still many questions regarding the role of NCPS during both normal and pathological formation of teeth and bone. The physicochemical characteristics of matrix proteins, as well as their temporal expression pattern and spatial distribution are key elements that determine their ability to interact with mineral, cells and other proteins. Identification of matrix constituents and mapping of their temporospatial pattern of expression are thus essential for determining their function and formulating coherent hypotheses on their mechanism(s) of action. Fibrillar collagen can be readily identified by its conspicuous structure. However, NCPs, in general, do not individually exhibit characteristic structural features that permit to identify them and morphologically determine their localization. Methods to identify them and reveal their presence are therefore required.

\section{Post-embedding colloidal-gold cytochemistry}

Cytochemistry is a form of biochemistry on section with the potential of resolving single molecules and represents a powerful imaging technique for correlating composition with structure. Its application to histological analyses has permitted the in situ identification and mapping of individual molecular constituents of a variety of cells and tissues. Among the methods available for cytochemistry, our laboratory has exploited the postembedding colloidal gold approach and pioneered its application to calcified tissues. Colloidal gold has been used for variety of applications but is more widely known for immunolabeling (Figure 1). For a detailed treatise of the principles, methods and applications of colloidal gold the reader is referred the book series edited by Hayat (1989a; 1989b; 1991) and to Bendayan (1995).

Colloidal gold has been coupled to enzymes to detect their substrates on sections. The theoretical principle of this approach resides on the selective binding of the enzyme to corresponding conformational arrangement of amino acids and linkages within substrate molecules. Enzyme-gold complexes have been used for cytochemistry of nucleic acids, extracellular matrix components and phospholipids (Bendayan 1989). We have successfully applied phospholipase A2-gold complexes to investigate the differential distribution of phospholipids in membranes of formative cells in various calcified tissues (Figure 2). Lectin-gold cytochemistry is per- 


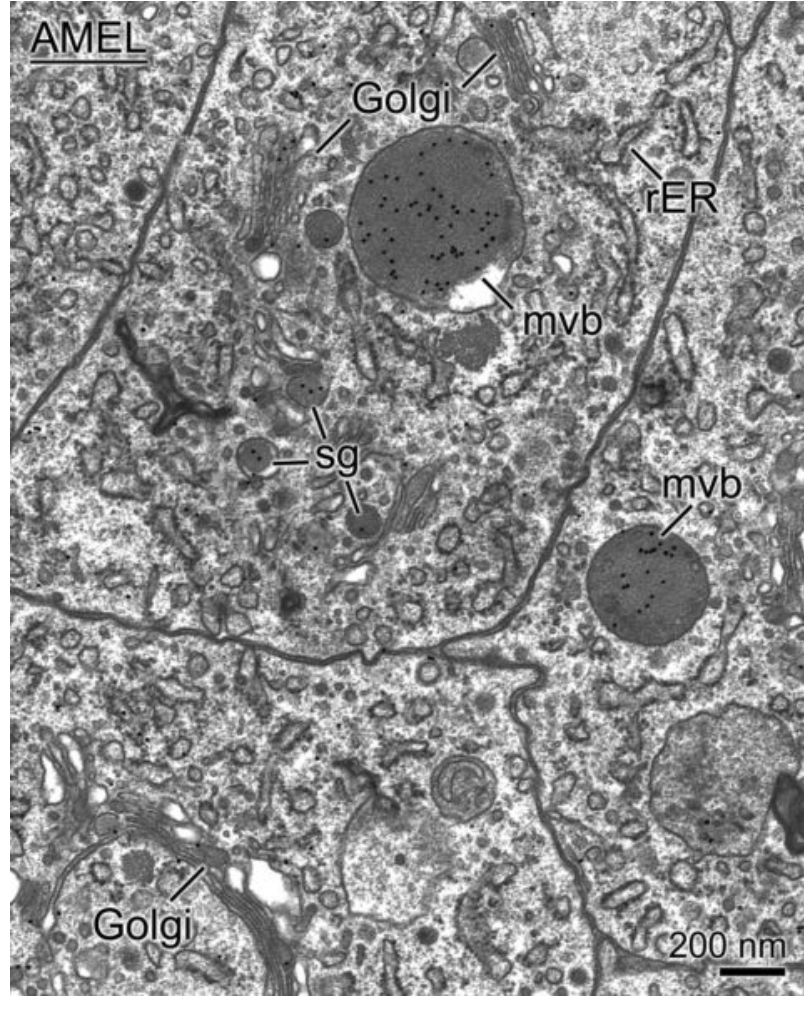

Figure 1. Application of colloidal gold to immunodetect amelogenin (AMEL) in secretory stage ameloblasts. Gold particles are distributed over the rough endoplasmic reticulum (rER), the Golgi apparatus, multivesicular bodies (mvb), and secretory granules (sg).

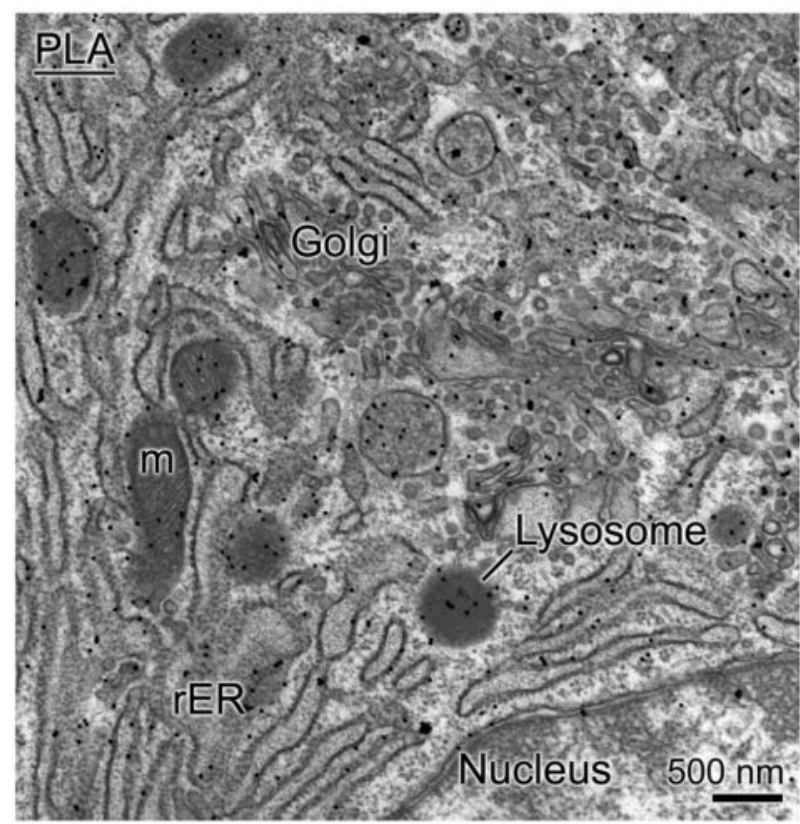

Figure 2. Cytochemical preparation with phospholipase A2-gold complex (PLA) reveals the presence of phospholipids in membranes of various cellular compartments in osteoblasts. $\mathrm{m}$, mitochondria; rER, rough endoplasmic reticulum.

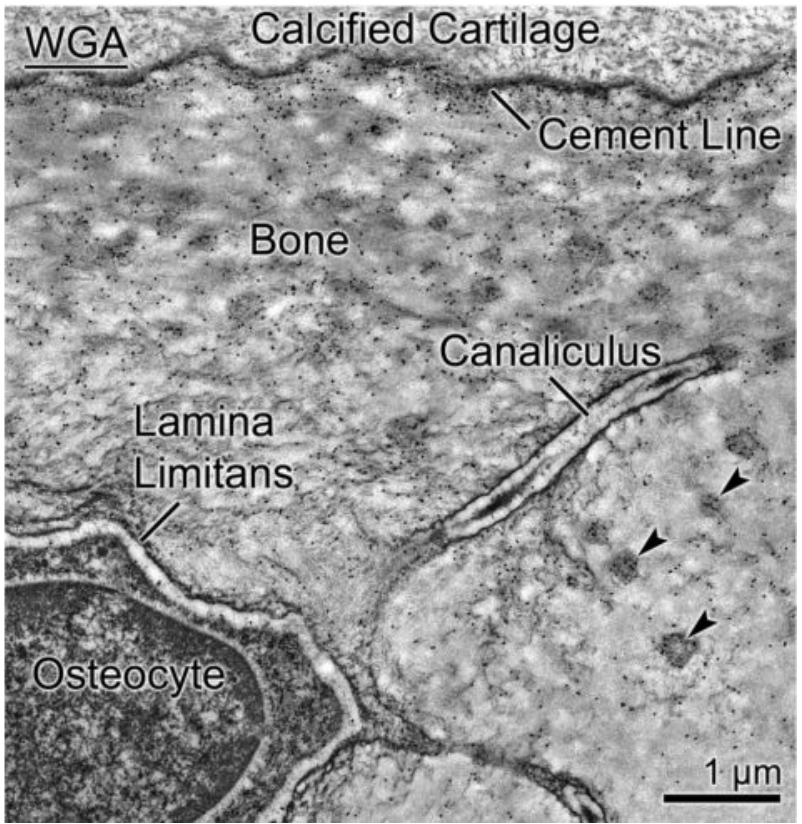

Figure 3. Lectin-gold cytochemistry with Wheat Germ Agglutinin (WGA) showing the accumulation of glyconjugates containing $\mathrm{N}$-acetyl-D-glucosamine/ $\mathrm{N}$-acetylneuraminic acid residues in interfibrillar matrix patches (arrowheads), and cement lines in bone.

formed to reveal and map the distribution of glycoconjugates by exploiting the specific recognition capacity of lectins for carbohydrate moieties on proteins. Marking of glycoconjugates can be carried out either directly with lectins coupled to colloidal gold or indirectly using native lectin followed either by a corresponding glycoprotein-gold complex or anti-lectin antibody revealed by protein A-gold. Since most NCPs are glycoproteins, we have used this approach to visualize their general distribution in calcified tissues, in vivo and in vitro (Nanci et al. 1996b; Bosshardt et al. 1998; Irie et al. 1998) (Figure 3). Albumin-gold complexes have been used to study vascular permeability (Ghitescu et al. 1988) and to visualize endocytotic activity in calcified tissue cells (Nanci et al. 1996a). Finally, colloidal gold labeling can be combined with radioautography to provides a time dimension component to cytochemical detections (Figure $4 \mathrm{~A}$ ) or with metal-based enzyme cytochemistry to identify the nature of subcellular compartments in which proteins are found (Figure 4 B) (Nanci et al. 1987a).

Colloidal gold labelings can be visualized at the light microscope level using differential contrast, large gold particles or silver enhancement. However, the high atomic number of gold and its 

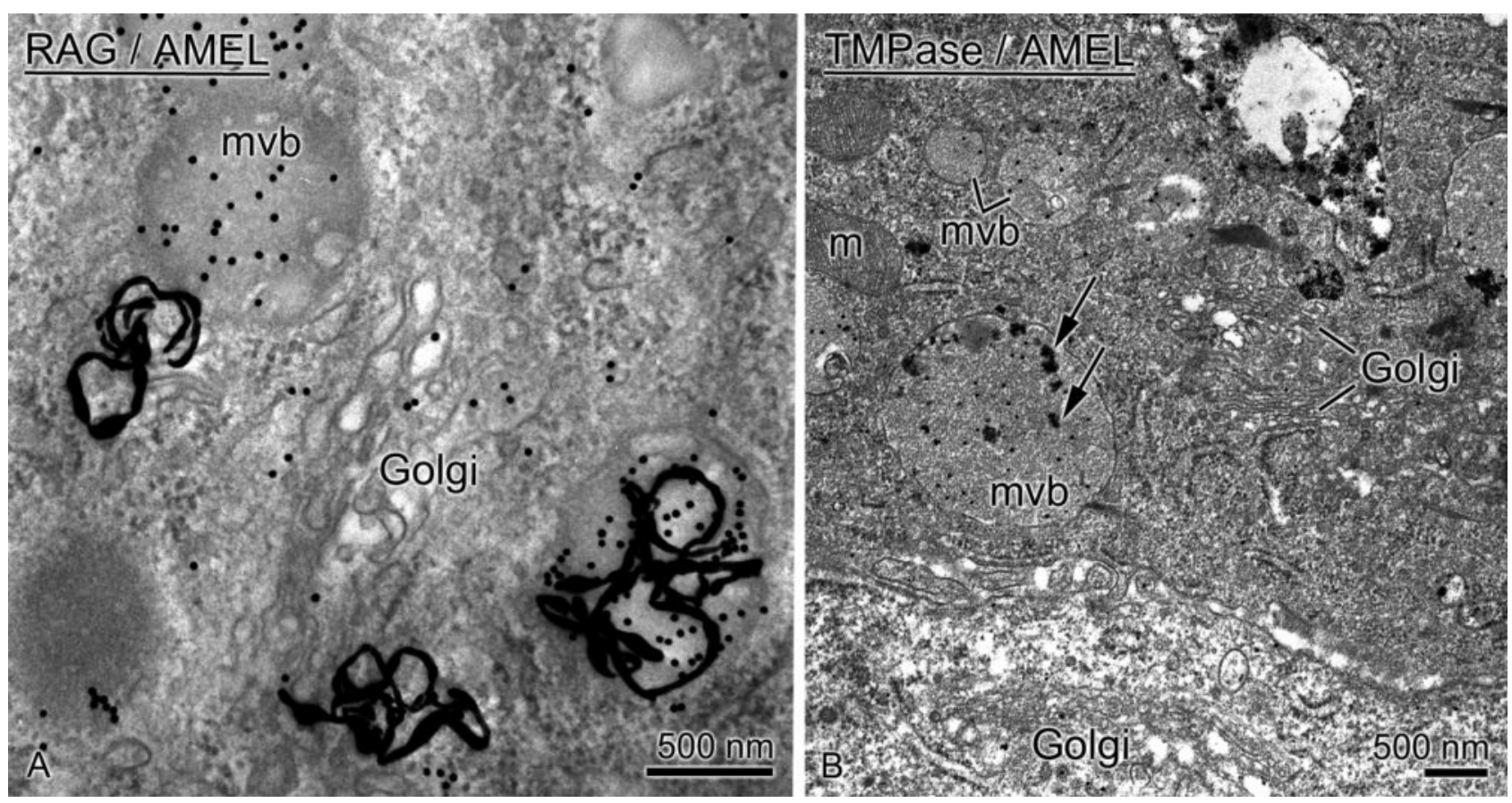

Figure 4. (A) Immunogold labeling for amelogenin (AMEL) combined with radioautography (RAG; filamentous silver grains) at 20 minutes after injection of ${ }^{3} \mathrm{H}$-methionine. Radiolabeling at such an early time interval suggests that the AMEL molecules in multivesicular bodies (mvb) from secretory stage ameloblasts are newly-synthesized proteins and likely derive from shunting of excess secretory products into the endosomal/lysosomal compartment prior to secretion. (B) Dual lead-based cytochemical detection of trimetaphosphatase (TMPase) activity (arrows) and immunolabeling preparation in maturation stage ameloblasts. The spotty enzyme activity (arrows) in some mvbs suggests their functional transition towards secondary lysosomes. $\mathrm{m}$, mitochondria.
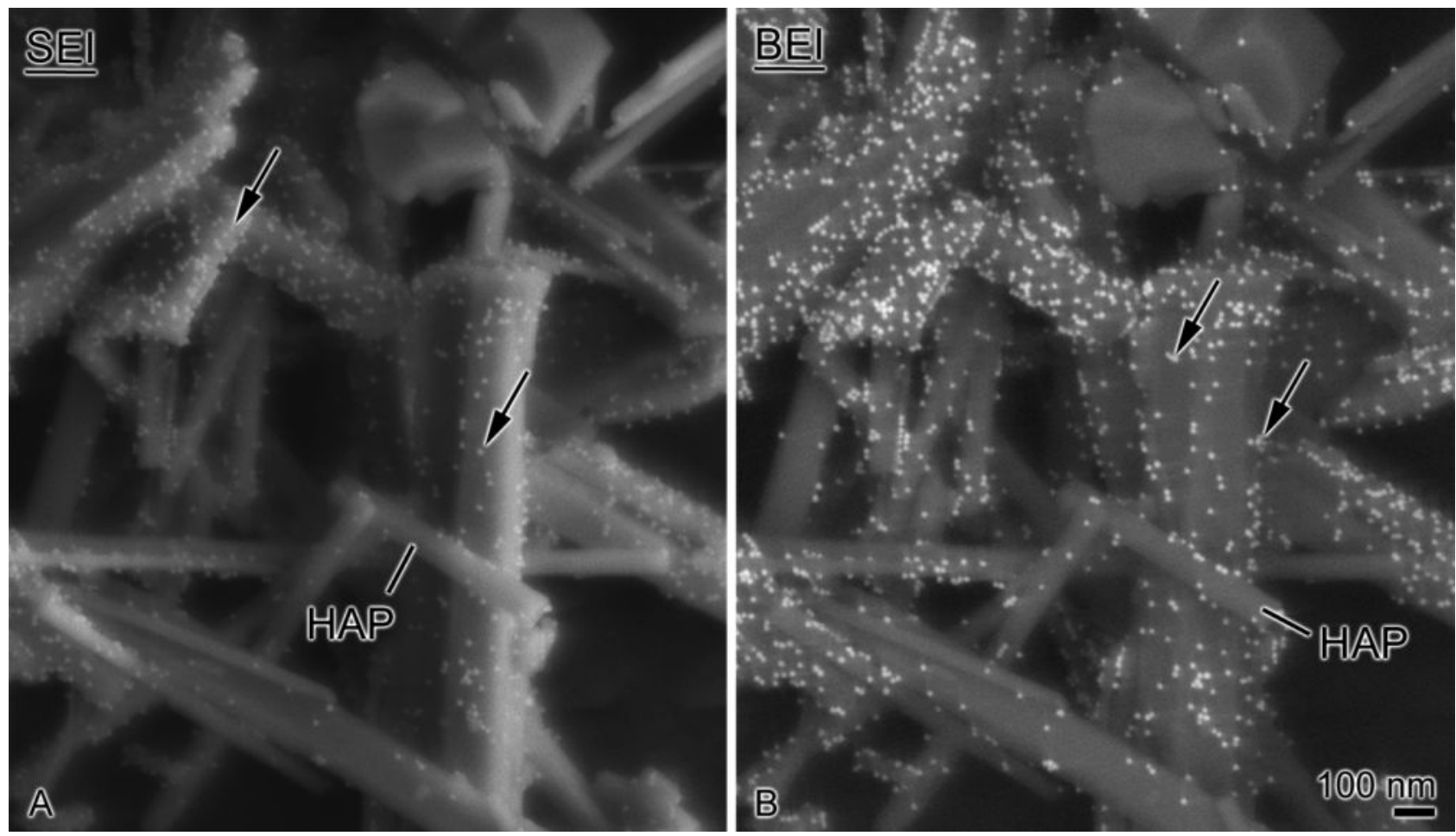

Figure 5. Scanning electron microscope micrographs of protein A-gold (arrows) adsorbed onto hydroxyapatite crystals (HAP) obtained by (A) secondary electron imaging (SEI) and (B) and backscattered electron imaging (BEI). While SEI provides more topographical information, the high compositional contrast of gold facilitates visualization of labelings by BEI under similar observation conditions. 


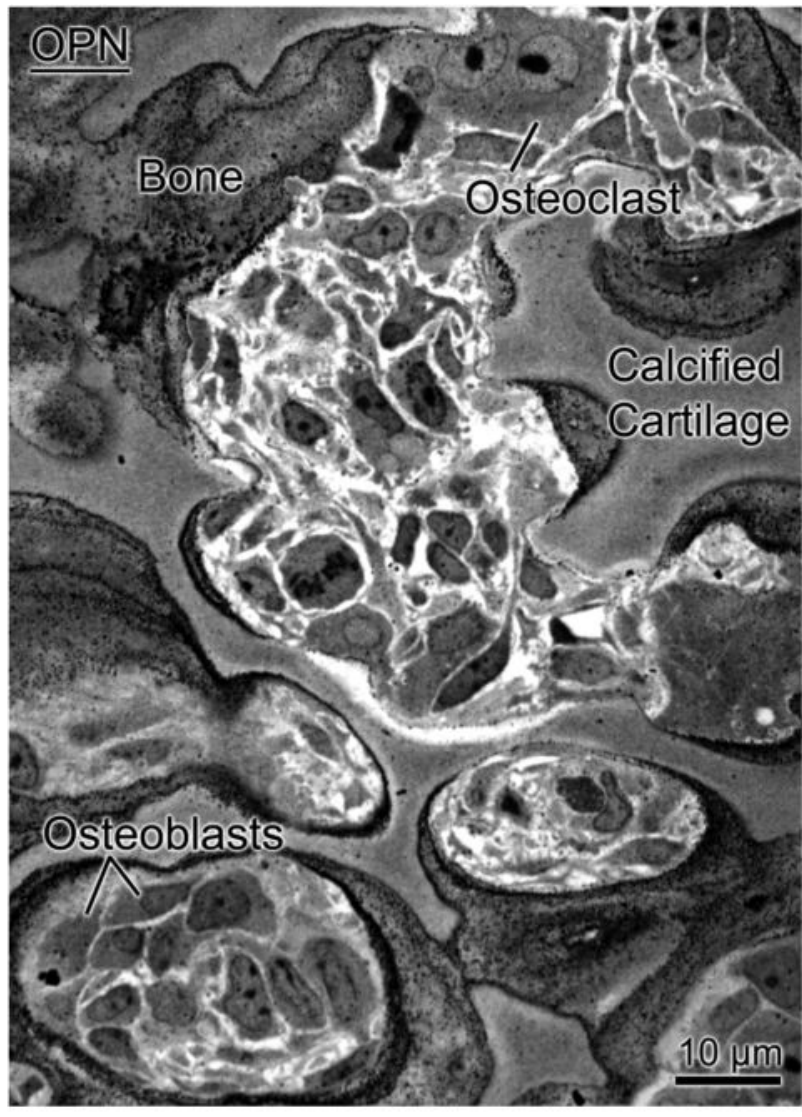

Figure 6. Immunogold labeling for osteopontin (OPN) on semi-thick section of rat bone observed in the scanning electron microscope using the backscattered electron imaging mode.

electron density make it an ideal marker for electron microscopy. Colloidal gold can be prepared in various sizes for multiple labelings and it can be conjugated to a variety of macromolecules inhouse. Most importantly, its particulate nature allows accurate identification of labeled structures and quantification of labeling density. The majority of colloidal gold applications at the electron microscope level have been for transmission electron imaging. However, colloidal gold labeled preparations can also be visualized in the scanning electron microscope using secondary (Figure 5) or backscatter electron imaging. While this latter approach is more conventionally used to identify and examine the distribution of molecules both on natural and exposed surfaces, it has also been advantageously applied to semi-thin tissue sections of plastic embedded tissues (Nanci et al. 1990). In this approach, the scanning electron microscope is used to obtain an overview of the labeling with

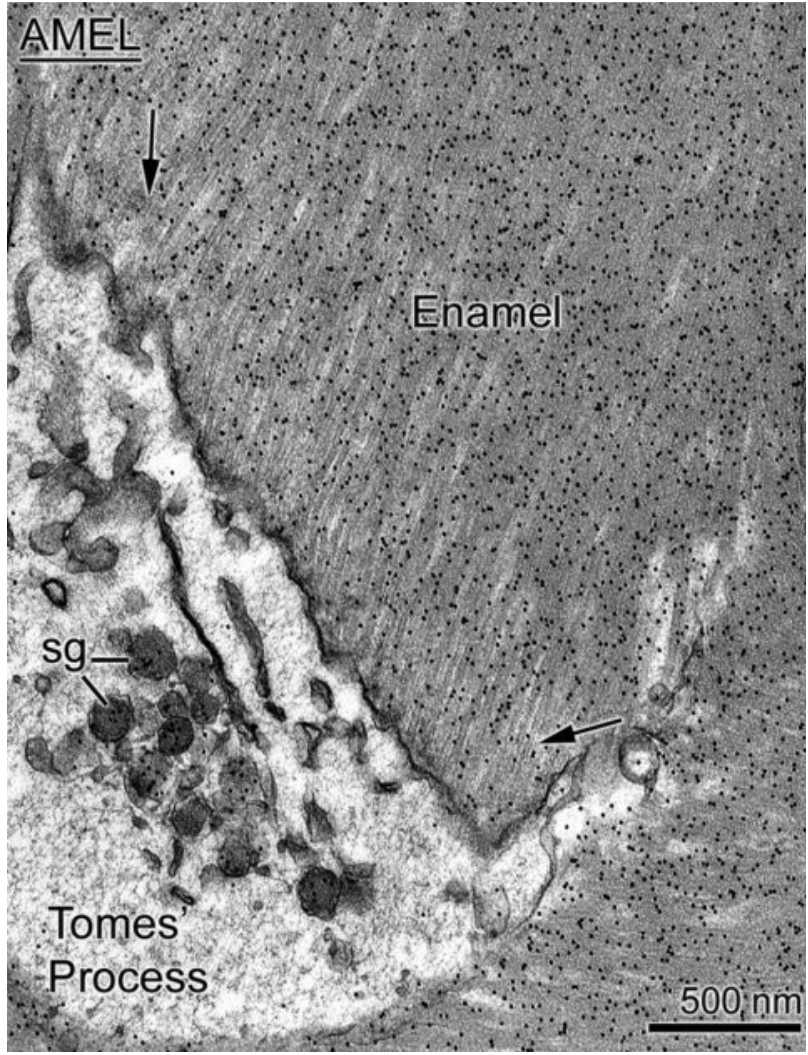

Figure 7. Immunogold labeling for amelogenin (AMEL) over the forming enamel layer. The enamel is penetrated by the apical extension (Tomes' process) of an ameloblast that contains immunoreactive secretory granules (sg). The labeling over enamel is uniformly distributed throughout the layer except along the secretory surface of the process (arrows) where there are fewer gold particles.

respect to cells and tissues, just like light microscope cytochemistry. However, the images obtained have more contrast and resolution, and contain more structural details at low magnification. Thus, labelings can be detected with more sensitivity and attributed with more reliability (Figure 6 ).

\section{Selected calcified tissue applications}

Initial immunogold studies on calcified tissues dealt with the distribution of enamel proteins in teeth (Figure 7) (Nanci et al. 1984a; 1984b; 1985) and osteocalcin in bone and dentin (Bianco et al. 1985; Camarda et al. 1987; Gorter de Vries et al. 1987). It has since been used to characterize the presence and distribution of a number of matrix molecules in normal and pathological calcified tissues of various animal species, ranging from invertebrates to mammals. In this paper, we will review some of our applications of postembedding colloidal gold immunocytochemistry to calcified tis- 
sues. These have been selected to demonstrate that the method can not only provide compositional information but also that it can be advantageously exploited to obtain functional information.

\section{Co-secretion of matrix proteins by ameloblasts}

The epithelially-derived ameloblasts forming enamel exhibit a structural organization consistent with active protein synthesis and secretion. The Golgi apparatus is extensive and occupies much of the supranuclear compartment (Nanci et al. 1993a; Smith and Nanci 1995). These cells direct their secretory granules toward two spatially distinct secretory sites, situated on an apical extension called Tomes' process, where they release their matrix proteins constitutively to build up interrod and rod enamel (Nanci and Warshawsky 1984). These proteins consists of two broad categories, AMEL and the larger and more hydrophilic nonamelogenins (reviewed in $\mathrm{Hu}$ et al. 2005). While AMEL accumulate in the forming enamel layer, nonamelogenins, which include AMBN, are shortlived and do not amass. Together, enamel matrix proteins regulate deposition and structuring of the mineral phase. Distinctive from collagen-based calcified tissues, enamel matrix proteins are eventually almost completely removed by extracellular enzymatic degradation to make place mineral growth (reviewed in Smith 1998).

It has for long been believed that enamel proteins slowly diffuse away from secretory surfaces, intermix, and randomize across the forming enamel layer over time (Smith and Nanci 1996). However, the situation has demonstrated to be more complex; following release from the cell, $A M E L$ and nonamelogenins assume differential distributions that appear to correlate with their proposed functions (Nanci et al. 1998). Intact AMEL and/or its fragments exist throughout the forming enamel layer but they are present in lowest abundance at enamel growth sites (Nanci et al. 1996b; 1998). Amelogenin forms supramolecular aggregates called nanospheres which pack among the apatite crystal throughout the forming enamel layer to regulate/stabilize their growth in width and thickness (Moradian-Oldak et al. 2002). AMBN shows an inverse distribution pattern compared to AMEL. That is, newly secreted molecules initially accumulate at enamel growth sites where crystals actively elongate while their fragments are found deeper within the enamel layer (Uchida et al. 1997; Dohi

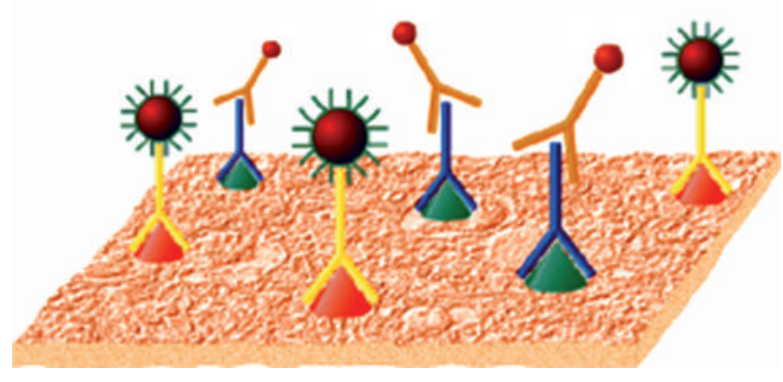

Figure 8. Schematic representation of double immunolabeling on the same side of the tissue section using protein $A$ and IgG complexed to two different sizes of colloidal gold to differentially reveal binding sites of the two primary antibodies.

et al. 1998; Nanci et al. 1998). The concentration of AMBN at these growth sites, and lack of formation of an enamel layer when the gene is inactivated (Fukumoto et al. 2004) suggest a role in regulating crystal elongation.

The matrix territoriality exhibited by $A M E L$ and AMBN can result from differential intracellular routing and secretion and/or different extracellular behaviors of the proteins when released into the forming enamel. To address this question, we have applied dual-immunogold labeling, on the same face of the thin section using two different sizes of gold (Figure 8), to visualize their presence and quantify the proportion of secretory granules in Tomes' processes containing one or both of these proteins (Figure 9) (Zalzal et al. 2008). Results from this first attempt to colocalize proteins at the ultrastructural level in ameloblasts show that AMEL and AMBN indeed co-distribute within the Golgi apparatus. Unexpectedly, this is not always the case for secretory granules from ameloblasts actively involved in building the enamel layer. The results show that nearly $70 \%$ of granules contain both AMEL and AMBN, $13 \%$ contain only AMBN and $1 \%$ only AMEL. Thus, quantitative analysis reveals the presence of an AMBN-enriched subpopulation, which suggests that there must be some regulated mechanism at the level of the Golgi apparatus for at times sorting and packaging AMBN into separate secretory granules. One possible mechanism to achieve predominance of nascent AMBN at enamel growth sites would be to boost release of AMBN by having the $13 \%$ of secretory granules in Tomes' processes that contain AMBN but no AMEL release their content at the same site where granules containing both proteins undergo exocytosis. 


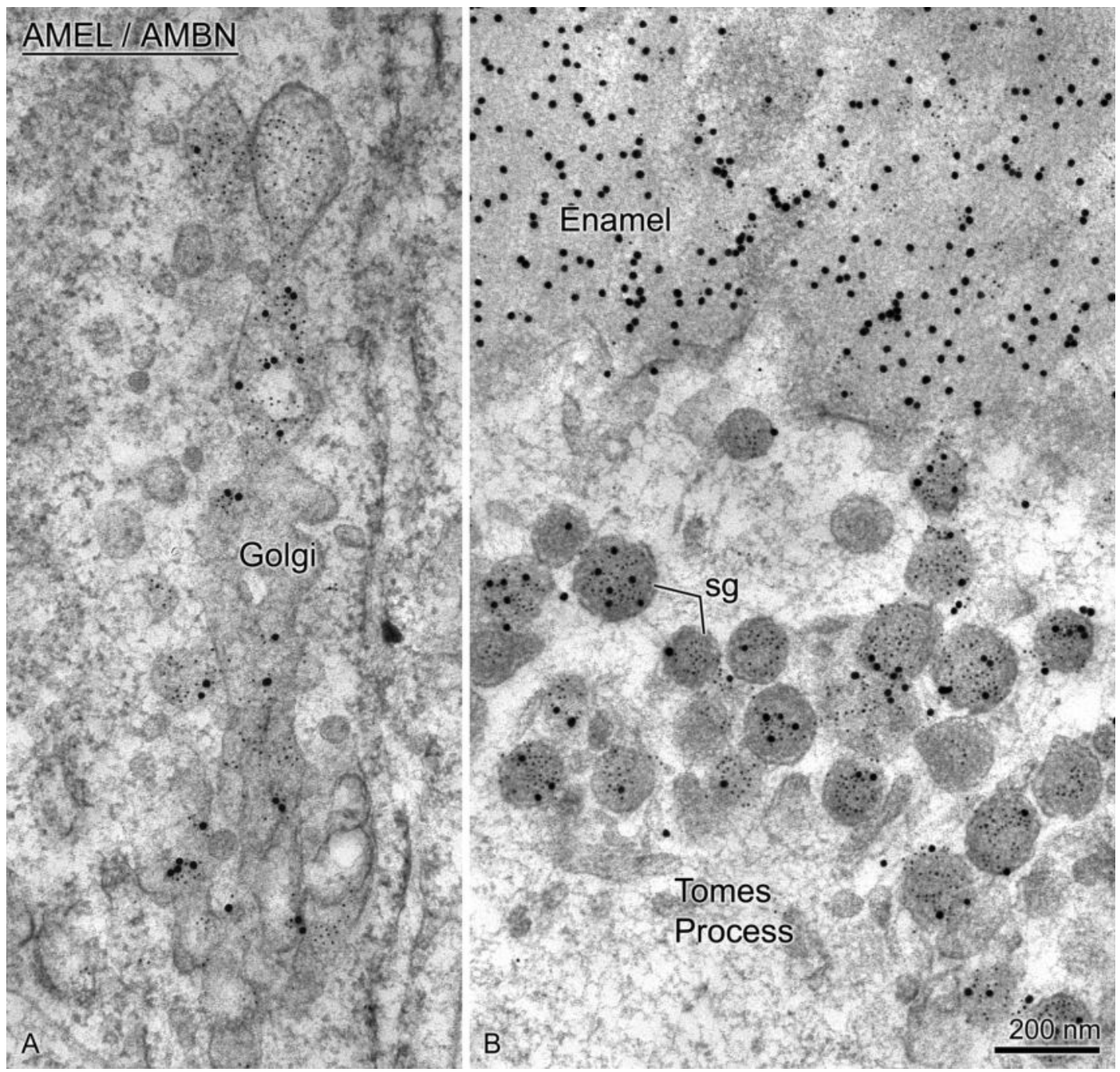

Figure 9. The intracellular routing of ameloblastin (AMBN, small gold particles) and amelogenin (AMEL, large gold particles) in secretory stage ameloblasts was revealed by dual-immunogold labeling. (A) AMBN and AMEL colocalize in the saccules of the Golgi apparatus. (B) The majority of secretory granules (sg) found in the apical extension of ameloblasts (Tomes' process) exhibit labeling for both AMBN and AMEL, however, an important proportion contain only AMBN and some granules neither protein.

However, other mechanisms such as direct/indirect implication of the plasma membrane along secretory surfaces and/or favored interaction with the growing extremity of enamel crystals may also be implicated in achieving differential distributions.

\section{Distribution of noncollagenous matrix proteins in bone}

It is now well-known that bone tissue from different anatomical sites, developmental stages, and species exhibit different organization and relative proportions of collagenous and NCPs components (Nanci 1999). The variation in bone matrix protein composition in flat and long bones has recently been suggested to reflect differences in mechanical and functional properties (van den Bos et al. 2008). Immunogold labeling has shown that both BSP and OPN appear at mineralization foci (Figure $10 \mathrm{~A}$ ) and thereafter pack in the spaces between collagen fibrils (Figure $10 \mathrm{~B}$ ). Although BSP has been reported to accumulate and colocalize with bone acidic glycoprotein-75 at sites of mineral nucleation (Gorski et al. 2004; Midura et al. 2004), a recent report revealed only slight mineral deficit in BSP knockout mice (Malaval et al. 2008). The presence of lectin cytochemistry and immunolabeling for BSP and OPN have further 


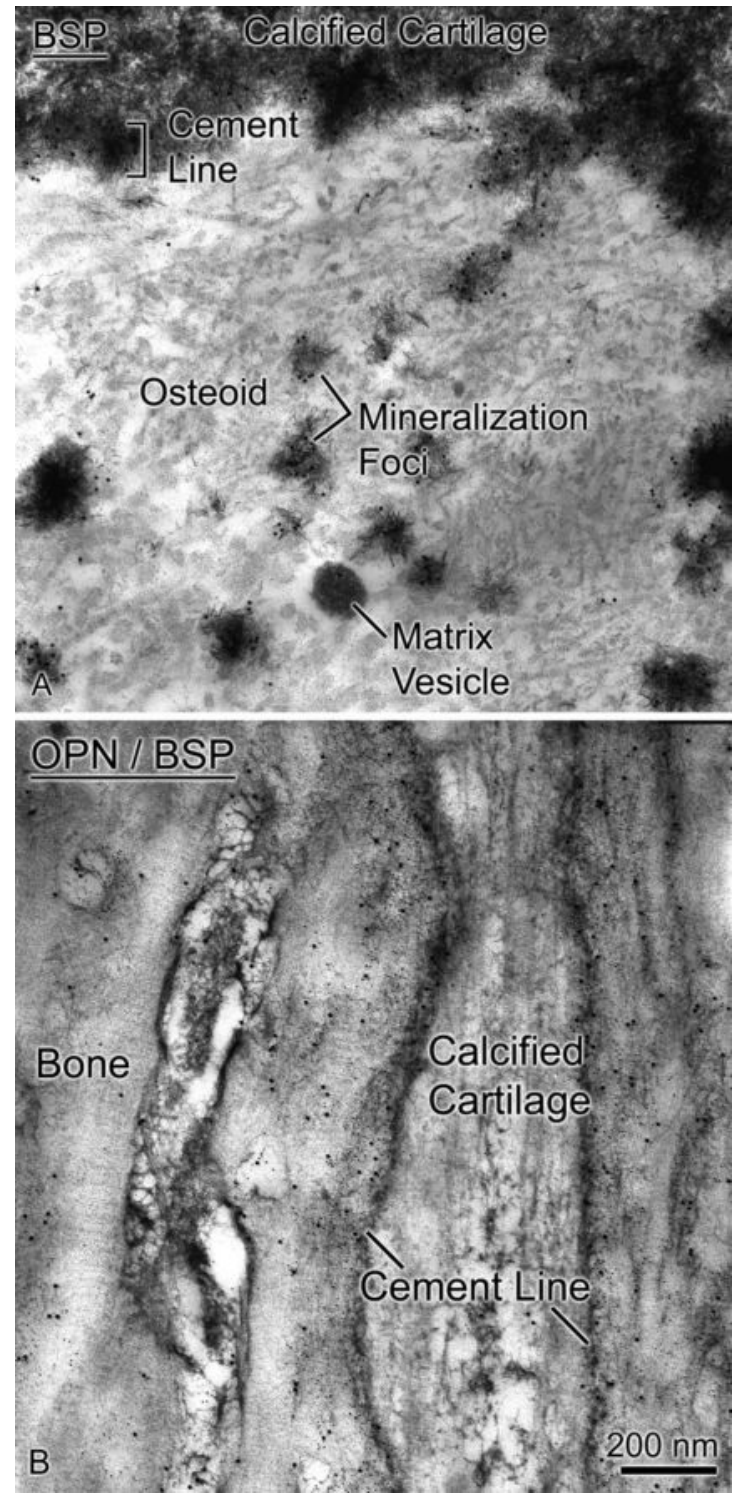

Figure 10. Distribution of bone sialoprotein (BSP) and osteopontin (OPN) in tibial bone. (A) BSP is found within mineralization foci in osteoid deposited onto a calcified cartilage spicule from the primary spongiosa. The cement line at the interface of the spicule and the forming bone is also immunoreactive for BSP. (B) Double immunolabeling for BSP (small gold particles) and OPN ) (large gold particles) reveals co-localization of both proteins in cement lines.

revealed that locally, within a same bone tissue there are areas that can be either poor or enriched in NCPs (Nanci 1999). One possible interpretation for this observation is that changes in the speed of formation of the tissue locally result in a different packing density of collagen and an ensuing variation in the amount of NCPs (Bosshardt et al. 1998). Consistent with this interpretation, woven bone which forms faster has a looser collagenous

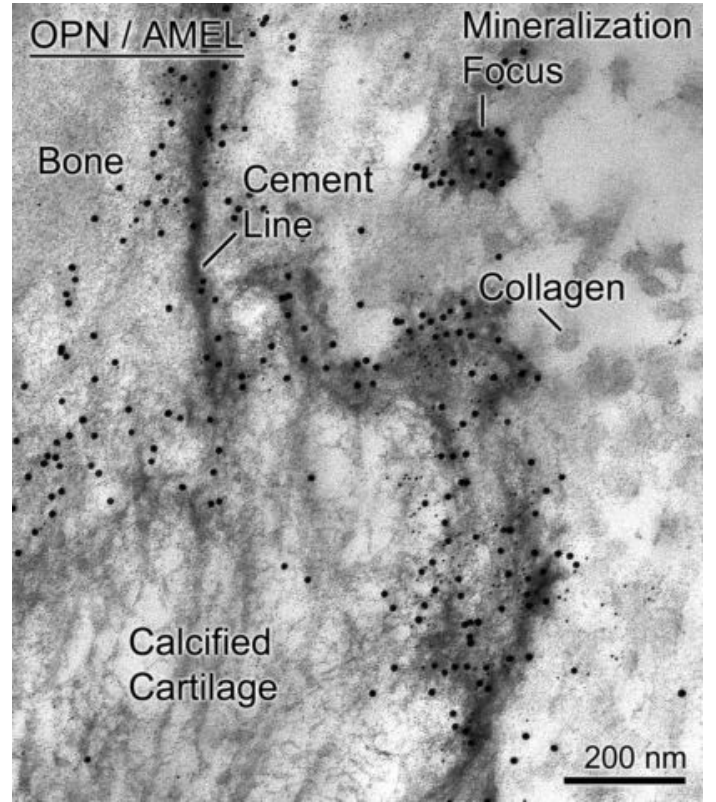

Figure 11. Double labeling with an antibody to osteopontin (OPN, large gold particles) and an antibody raised against a bovine amelogenin peptide (AMEL, small gold particles). Binding sites for both antibodies are detected over cement lines and in mineralization foci. While such co-localization is exciting, it must be taken with caution because the anti-peptide antibody used may cross-react with other proteins, and AMEL has not been detected biochemically in bone. All that can be concluded is that there is a selective binding of the anti-peptide antibody to structures that contain OPN.

meshwork matrices and more NCPs (Gorski 1998; discussed in Nanci 1999). Accumulation of NCPs in spaces among collagen fibrils may serve to impart cohesion to the mineralized bone matrix.

There is also an apparent accumulation of BSP and OPN in cement lines and laminae limitantes (Chen et al. 1994; Riminucci et al. 1995; McKee and Nanci 1996b). It has been proposed, using en bloc staining with the cationic dye malachite green to retain and stain polyanionic molecules, that cement lines and the interfibrillar patches form a continuous network (Riminucci et al. 1995). The fact that these two matrix compartments exhibit very close densities of immunolabeling for various proteins constituting them, such as BSP and OPN, is certainly consistent with this concept. Cement lines are still present in OPN knockout mice (Rittling et al. 1998) suggesting the existence of a more fundamental component in these planar, interfacial structures. In this regard, we have observed that an antibody raised against a synthetic bovine $A M E L$ peptide binds selectively to cement lines 


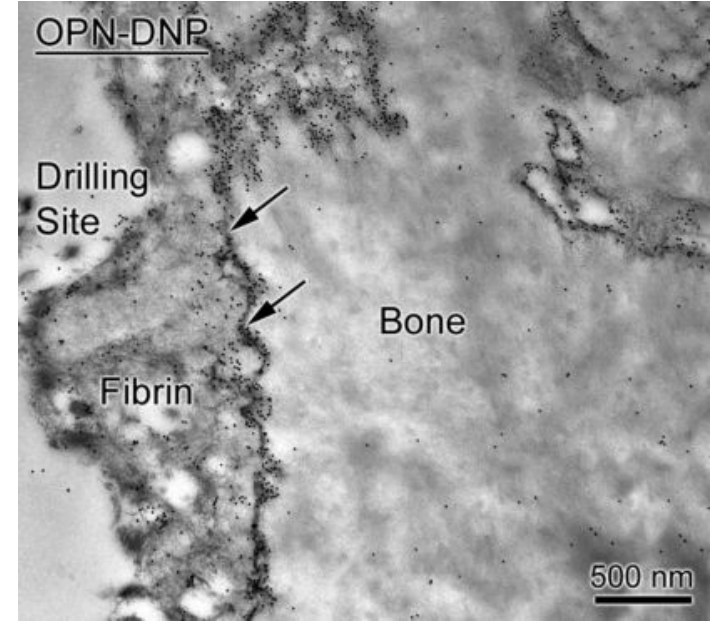

Figure 12. Immunolabeling for dinitrophenol (DNP) following infusion of DNP tagged-osteopontin (OPN) through a bony window in the rat hemimandible shows the accumulation of the tagged protein on mineralized surfaces exposed (arrows) during the drilling procedure.

(Figure 11). Although the binding may not be specific, its selectivity raises the possibility that there may be a unique component and/or environment (protein-protein interactions) at these interfaces. Such labeling is also consistent with emerging evidence that NCPs in enamel and bone have a common ancestral origin (Huq et al. 2005; Sire et al. 2005). Accumulation of BSP and OPN similar to cement lines also occur at bone-biomaterial interfaces and this has been associated with successful osseointegration (Kawaguchi et al. 1993; Nanci and McKee 1994; McKee and Nanci 1996c). Clearly, the accumulation of NCPs on natural mineralized surfaces or artificial ones can have an influence on local cell dynamics by mediating cell attraction and adhesion, and activating signaling pathways.

\section{Tracer studies and functional relationships}

A number of bone matrix components are normally found in the circulation but these have been generally regarded as metabolic byproducts of bone formation and resorption that have no function at distant sites. A light microscope study showed that intravenously administered ${ }^{125}$ I-OPN can be transported via the circulation and deposited into a number of calcified tissues (VandenBos et al. 1999). Despite the fact that the study was carried out at supraphysiological conditions, its results nonethe- less highlighted the possibility that OPN in calcified tissues is derived not only from local cellular sources but it may also be recruited from outside the local environment via the circulation.

To determine whether circulating bone matrix proteins can participate in bone formation events, we have carried out tracer studies. The molecules were tagged by dinitrophenylation, which results in the covalent addition of dinitrophenol (DNP) groups to $\varepsilon$-lysine residues (Little and Eisen 1967). This reaction generally does not alter the physiochemical properties of the tagged molecules (Kessler et al. 1982). The tagged proteins are then revealed by immunodetection of DNP groups. Detection is highly sensitive because several DNP groups can be attached to a protein and the antigenicity of those groups is resistant to tissue processing conditions (Kessler et al. 1982; Ghitescu and Bendayan 1992). Tracer protocols generally involve intravenous injections of relatively large amounts of proteins in order to saturate tissues throughout the body in quantities large enough to be detected. Such large dosages rarely are physiological. Our laboratory has developed an experimental system that allows the controlled administration of biological and chemical agents through a surgically-created window in rodent bones ( $\mathrm{Vu}$ et al. 1999; Orsini et al. 2001; Wazen et al. 2006). Administration of DNP-tagged molecules through surgically created holes in bones permits tracer experiments to be carried out at near physiological concentrations, to distinguish the administered molecules from endogenous ones, and to follow them over time.

Infusion of DNP-tagged OPN through such windows and its ultrastructural localization using immunogold labeling showed that it is incorporated into various compartments of bone where endogenous OPN normally accumulates and acts, including mineralization foci, interfibrillar patches and cement lines (Nanci 1999; 2004) (Figure 12). This suggests that the action of bone matrix proteins extends beyond the microenvironment where they are produced and vectorially secreted. Thus, circulating molecules may have a more important impact than so far suspected, particularly on initial mineralization events for which few molecules are generally required.

We have also applied this approach to probe the function of predicted functional groups on the BSP molecule (Wazen et al. 2007). Our current under- 
standing of the properties, activities, and molecular structure of BSP derives mainly from in vitro assays and in silico predictions. BSP contains two glutamic acid rich regions [poly $(E)$ ] in the N-terminal half of the molecule (Hunter and Goldberg 1993; 1994; Harris et al. 2000; Tye et al. 2003). These domains are believed to be partially responsible for the nucleating activity of BSP and could also be involved in the binding capacity of BSP to hydroxyapatite (Oldberg et al. 1988; Stubbs, III et al. 1997; Goldberg et al. 2001). To test this latter possibility, the poly (E) domains were mutated for polyalanine [poly (A)]. Dinitrophenol-tagged prokaryote recombinant BSP and its mutated form were infused through a bony window in the rat mandibular bone. The presence of tagged molecules along the surgically exposed bone surfaces, was revealed and determined using quantitative colloidal gold immunolabeling. The results show that substitution of poly (E) domains by poly $(A)$ has a major impact and reduces by $73 \%$ its binding to the organic and/or mineral phase of bone.

Both endogenous BSP and OPN are immunodetected along the exposed surfaces of the bony window (Nanci et al. 2004; Wazen et al. 2007) This demonstrates that the observed binding of tagged molecules onto these surfaces is a normal event and is not induced by dinitrophenylation or by the infusion process itself. The body seems to respond to bone damage by quickly sequestering and accumulating at least these two NCPs on exposed mineralized surfaces. Absence of osteoblasts on these surfaces, paucity of inflammatory cells such as macrophages (McKee and Nanci 1996a) in their immediate vicinity, and incorporation of tagged molecules administered at a distance indicate that circulating molecules, from blood or the tissue fluid microenvironment, are likely sources for these proteins. Indeed, it has been proposed that circulating NCPs also contribute to the formation of cement lines at natural bone interfaces and at the boneimplant interface (Nanci et al. 2000; 2004).

These results are particularly pertinent because they have been obtained in context of the whole animal biology where the physiological environment is complex and multifactorial. It should be noted that in vivo the behavior of a protein will not only depend on its physicochemical properties but will also reflect the modulation of these properties by the various tissue components it is exposed to. For example, the effect of proteins on mineralization can vary depending on whether they are in solution or bound to collagen (Saito et al. 1998; 2000). Also, affinity of a protein for hydroxyapatite can be enhanced through interactions with other proteins (Yin et al. 2005). In addition, it has recently been shown that adsorption of bovine serum albumin to hydroxyapatite is influenced by the degree of complexing of calcium ions to the protein (Kandori et al. 2005), a factor which is surely pertinent in vivo. Indeed, regional interactions may be one way by which proteins exert multiple behaviors.

Several strategies exist to elucidate gene function. One approach is to create animals that are null for one or more genes (knockout), express a mutated (insertions/deletions) gene or reexpress a full-length or truncated version of a gene product within a null background (knockin), or overexpress one or more specific gene products (transgenic). Gene transfer is another efficient method to differentially express proteins and gain insights into their function. We recently have exploited the surgically-created bony window model to infuse lentiviral vectors and generate local transgenic conditions in mandibular and tibial bone (Wazen et al. 2006) (Figure 13). Such a capacity is of great interest because it allows bypassing potential developmental compensatory mechanisms that have been observed in some $\mathrm{KO}$ and transgenic mouse models. It is also particularly advantageous because it allows to locally knockout expression of selected proteins using siRNA technology, overexpress proteins or express mutated forms in normal and pathological animal models that are not limited to mice.

\section{Pathological and drugs alterations of protein distribution}

One pathological alteration we have examined using immunocytochemistry is the bone matrix calcification defects during diet-induced hypocalcemia which are similar to those observed in rickets and osteomalacia (Mocetti et al. 2000). There were no major changes in the pattern of protein distribution of $\mathrm{BSP}$, osteocalcin, and OPN or concentration at labeled sites that could be inferred from qualitative observation. Immunocytochemically, the most conspicuous difference in labeling between hypocalcemic and control rats was the presence of many mineralization foci, intensely immunoreactive for the three proteins in the thickened osteoid (Figure 14). The abundance of matrix vesicles and the presence of these foci indicate that initiation of miner- 


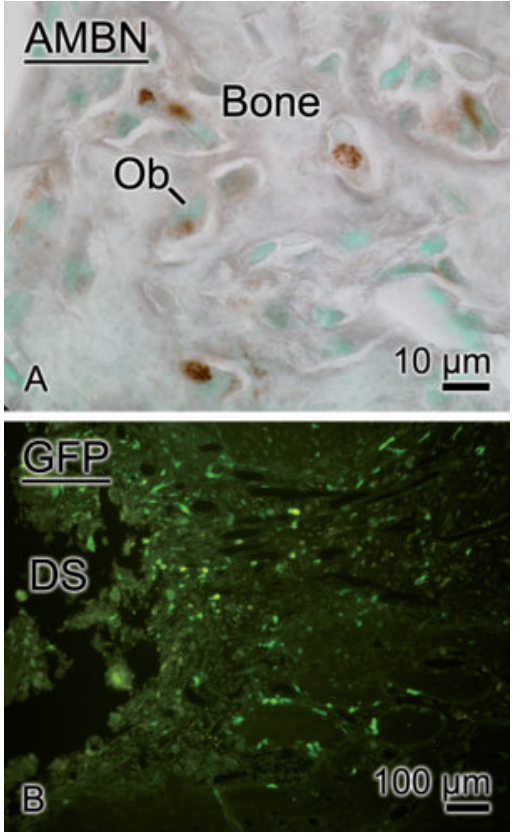

Figure 13. Local infusion of lentiviral vectors for amelobastin (AMBN) and green fluorescent protein (GFP) through bony windows. This local gene transfer results in $(A)$ expression of the enamel protein (AMBN) by osteoblasts (Ob) in newly-forming bone in the rat hemimandible, and (B) GFP expression by osteogenic cells in proximity to the drilling site (DS) in tibial bone.

alization must have occurred; however, its progression was clearly hampered. The abundance of osteoid tissue and the intense immunolabeling for NCPs in mineralization foci further suggest that the reduced availability of calcium, rather than an incompetent organic matrix, is the major factor for the alteration in mineralization observed in the hypocalcemic rat model.

The administration of drugs that have the capacity to alter protein synthesis and secretion is a powerful approach that can provide significant information on the behavior of proteins The basal lamina that separates ameloblasts from maturing enamel is rich in glycoconjugates (Nanci et al. 1987b; 1993b). We have infused tunicamycin through a bony window in the rat hemimandible to study the role of glycoproteins on the assembly and function of this basal lamina (Orsini et al. 2001). Tunicamycin is an antibiotic that interferes with $\mathrm{N}$ glycosylation and that has significant side effects when used systemically. Noteworthy, the infused animals exhibited none of the physical discomfort normally associated with systemic administration.

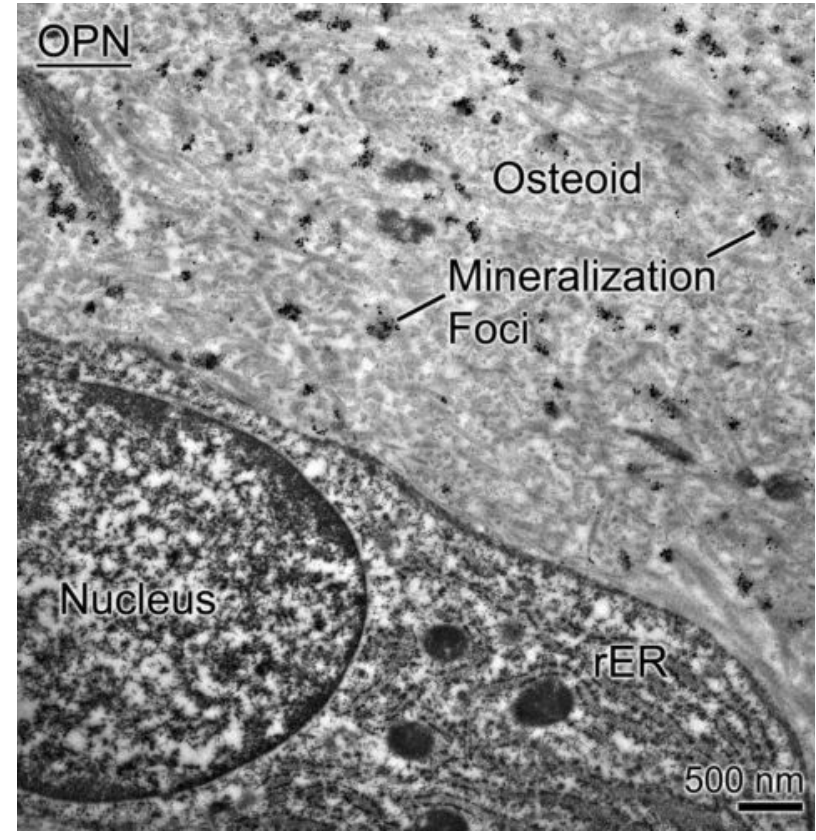

Figure 14. The increased osteoid in bone from hypocalcemic rats contains an abundance of mineralization foci that label for osteopontin (OPN) but this osteoid does not progress normally into a mineralized bone layer. Here we see an osteocyte completely surrounded by osteoid. rER, rough endoplasmic reticulum.

Under the influence of tunicamycin, the basal lamina became irregular and exhibited structural alterations. Lectin-gold cytochemistry revealed changes in the distribution of glycocomponents. Immunolabeling for albumin showed an abundant presence of this serum protein in the maturing enamel layer, a protein which is normally excluded from the layer. These results lend support to the concept that one function of the basal lamina is to act as a selective filter that lets proteins out of the enamel layer while preventing inflow of proteins during the maturation process.

Another example on how drugs and immunolabeling can be advantageously combined is the use of synthesis and secretion inhibitors to study the extracellular behavior of proteins. As indicated above, AMBN accumulates at enamel growth sites and has a short half life. The accumulation was demonstrated by quantitative immunolabeling (Nanci et al. 1998). The short half life was determined by mapping the distribution of AMBN at enamel growth sites when secretion of new AMBN was arrested using brefeldin A or cycloheximide. 


\section{Conclusions}

While there have been major improvements in sensitivity and resolution of LM-based cytochemical reactions, mainly using fluorophores, only electron microscope approaches are able to provide precise and direct correlation of proteins with subcellular compartments, cell and tissue structure. Colloidal gold cytochemistry is a reliable and quantitative approach to achieve such outcome. Used in conjunction with animal models and experimental manipulations, it can also provide significant functional and temporal-spatial information on the fate of matrix proteins. Thus, over the years, colloidal gold cytochemistry has evolved from a purely descriptive approach to a more analytical one.

Despite major progress in our knowledge on calcified tissues, the mechanisms by which NCPs achieve their functions are still not completely understood. Data have been often deduced and tested using in vitro model systems that do not always reflect the complex in vivo biological environment. This is particularly true for the multivariate mineralization process, which evolves within a systemic and dynamic physiological environment. Future studies are expected to provide correlation between functional domains and specific molecular and histological mineralization events. Such fundamental information on the function of NCPs is necessary not only for understanding the basic biology of hard tissue formation, but also for other potential applications in tissue engineering and regenerative medicine.

In order to probe further function of matrix proteins in bones and teeth, we have developed a bony window system to carry out various experimental manipulations, in the context of the whole animal biology (Vu et al. 1999; Orsini et al. 2001; Nanci et al. 2004; Wazen et al. 2007). The combination of colloidal gold immunolabeling and the bony window has allowed us to uniquely look at whether circulating NCPs can integrate the same sites where vectorially secreted NCPs normally incorporate, thereby participating in a similar manner to mineralization events. Of particular interest, this has also allowed to test in vivo proposed mineral binding domains of BSP and evaluate quantitatively their implication. Thus, this approach offers a powerful yet simple system in which amino acid motifs, posttranslational modifications and derived peptides can be tested for function and therapeutic potential in an environment that reflects the complex nature of the body, both in normal and genetically altered animal models.

\section{Acknowledgements}

The work reviewed in this paper was supported over the years by the Canadian Institutes of Health Research. C. Nishio is a recipient of a fellowship from the Department of Foreign Affairs of Canada.

\section{References}

Albeck S, Addadi L, Weiner S. Regulation of calcite crystal morphology by intracrystalline acidic proteins and glycoproteins. Connect Tissue Res 1996; 34-5: 419-24.

Bendayan M. The enzyme-gold cytochemical approach: A review. In: Hayat MA, editor. Colloidal gold: Principles, methods, and applications. San Diego: Academic Press Inc 1989. p. 117-47.

Bendayan M. Colloidal gold post-embedding immunocytochemistry. Prog Histochem Cytochem 1995; 29: 1-159.

Bianco P, Hayashi Y, Silvestrini G, Termine JD, Bonucci E. Osteonectin and GLA-protein in calf bone: Ultrastructural immunohistochemical localization using the protein A-gold method. Calcif Tissue Int 1985; 37: 684-86.

Bosshardt DD, Zalzal S, McKee MD, Nanci A. Developmental appearance and distribution of bone sialoprotein and osteopontin in human and rat cementum. Anat Rec 1998;250:1-21.

Camarda AJ, Butler WT, Finkelman RD, Nanci A. Immunocytochemical localization of gamma-carboxyglutamic acid-containing proteins (osteocalcin) in rat bone and dentin. Calcif Tissue Int 1987; 40: 349-55.

Chen J, McKee MD, Nanci A, Sodek J. Bone sialoprotein mRNA expression and ultrastructural localization in fetal porcine calvarial bone: comparisons with osteopontin. Histochem J 1994;26: 67-78.

Dohi N, Murakami C, Tanabe T, Yamakoshi Y, Fukae M, Yamamoto Y, et al. Immunocytochemical and immunochemical study of enamelins, using antibodies against porcine 89-kDa enamelin and its Nterminal synthetic peptide, in porcine tooth germs. Cell Tissue Res 1998;293:313-25.

Fisher LW, Torchia DA, Fohr B, Young MF, Fedarko NS. Flexible structures of SIBLING proteins, bone sialoprotein, and osteopontin. Biochem Biophys Res Commun 2001;280: 460-5.

Fukumoto S, Kiba T, Hall B, Iehara N, Nakamura T, Longenecker G, et al. Ameloblastin is a cell adhesion molecule required for maintaining the differentiation state of ameloblasts. J Cell Biol 2004; 167:973-83.

Ghitescu DL, Galis Z, Simionescu M, Simionescu N. Differentiated uptake and transcytosis of albumin in successive vascular segments. J Submicrosc Cytol Pathol 1988; 20: 657-69.

Ghitescu L, Bendayan M. Transendothelial transport of serum albumin: A quantitative immunocytochemical study. J Cell Biol 1992;117: 745-55.

Goldberg HA, Warner KJ, Li MC, Hunter GK. Binding of bone sialoprotein, osteopontin and synthetic polypeptides to hydroxyapatite. Connect Tissue Res 2001;42:25-37.

Gorski JP. Is all bone the same? Distinctive distributions and properties of non-collagenous matrix proteins in lamellar vs. woven bone imply the existence of different underlying osteogenic mechanisms. Crit Rev Oral Biol Med 1998;9:201-23.

Gorski JP, Wang A, Lovitch D, Law D, Powell K, Midura RJ. Extracellular bone acidic glycoprotein-75 defines condensed mesenchyme regions to be mineralized and localizes with bone sialoprotein during intramembranous bone formation. J Biol Chem 2004; 279:25455-63.

Gorter de Vries I, Quartier E, Boute P, Wisse E, Coomans D. 
Immunocytochemical localization of osteocalcin in developing rat teeth. J Dent Res 1987;66:784-90.

Harris NL, Rattray KR, Tye CE, Underhill TM, Somerman MJ, D'Errico $J A$, et al. Functional analysis of bone sialoprotein: identification of the hydroxyapatite-nucleating and cell-binding domains by recombinant peptide expression and site-directed mutagenesis. Bone 2000; 27:795-802.

Hayat MA. Colloidal Gold: Principles, Methods and Applications, Vol. 1. San Diego, California: Academic Press Inc.; 1989a.

Hayat MA. Colloidal Gold: Principles, Methods and Applications, Vol. 2. San Diego, California: Academic Press Inc.; 1989b.

Hayat MA. Colloidal Gold: Principles, Methods and Applications, Vol. 3. San Diego, California: Academic Press Inc.; 1991.

$\mathrm{Hu}$ JC, Yamakoshi $Y$, Yamakoshi $F$, Krebsbach PH, Simmer JP. Proteomics and genetics of dental enamel. Cells Tissues Organs 2005; 181:219-31.

Hunter GK, Goldberg HA. Modulation of crystal formation by bone phosphoproteins: Role of glutamic acid-rich sequences in the nucleation of hydroxyapatite by bone sialoprotein. Biochem Pharmaco 1994; 302:175-9.

Hunter GK, Goldberg HA. Nucleation of hydroxyapatite by bone sialoprotein. Proc Natl Acad Sci USA 1993;90:8562-65.

Huq NL, Cross KJ, Ung M, Reynolds EC. A review of protein structure and gene organisation for proteins associated with mineralised tissue and calcium phosphate stabilisation encoded on human chromosome 4. Arch Oral Biol 2005; 50:599-609.

Irie K, Zalzal S, Ozawa H, McKee MD, Nanci A. Morphological and immunocytochemical characterization of primary osteogenic cell cultures derived from fetal rat cranial tissue. Anat Rec 1998;252: 554-67.

Kandori K, Masunari A, Ishikawa T. Study on adsorption mechanism of proteins onto synthetic calcium hydroxyapatites through ionic concentration measurements. Calcif Tissue Int 2005;76:194-206.

Kawaguchi $\mathrm{H}$, McKee MD, Okamoto H, Nanci A. Immunocytochemical and lectin-gold characterization of the interface between alveolar bone and implanted hydroxyapatite in the rat. Cells Mater 1993;3 337-50.

Kessler KF, Barth RF, Wong K-P. Physicochemical studies of dinitrophenylated bovine serum albumin. Int J Pept Protein Res 1982;20: 73-80.

Little JR, Eisen HN. Preparation of immunogenic 2,4-dinitrophenyl and 2,4,6-trinitrophenyl proteins. In: Williams CA, Chase MW, editors. Methods in Immunology and Immunocytochemistry, Vol. 1. New York: Academic Press, Inc.; 1967. p. 128-33.

Malaval L, Wade-Gueye NM, Boudiffa M, Fei J, Zirngibl R, Chen F, et al. Bone sialoprotein plays a functional role in bone formation and osteoclastogenesis. J Exp Med 2008;205:1145-53.

McKee MD, Nanci A. Secretion of osteopontin by macrophages and its accumulation at tissue surfaces during wound healing in mineralized tissues: A potential requirement for macrophage adhesion and phagocytosis. Anat Rec 1996a;245:394-409.

McKee MD, Nanci A. Osteopontin: An interfacial extracellular matrix protein in mineralized tissues. Connect Tissue Res 1996b;35:197205

McKee MD, Nanci A. Osteopontin at mineralized tissue interfaces in bone, teeth and osseointegrated implants: ultrastructural distribution and implications for mineralized tissue formation, turnover and repair. Microsc Res Tech 1996c; 33: 141-64.

Midura RJ, Wang A, Lovitch D, Law D, Powell K, Gorski JP. Bone acidic glycoprotein-75 delineates the extracellular sites of future bone sialoprotein accumulation and apatite nucleation in osteoblastic cultures. J Biol Chem 2004; 279:25464-73.

Mocetti P, Ballanti P, Zalzal S, Silvestrini G, Bonucci E, Nanci A. A histomorphometric, structural, and immunocytochemical study of the effects of diet-induced hypocalcemia on bone in growing rats. Histochem Cytochem 2000;48:1059-77.

Moffatt P, Smith CE, Sooknanan R, St-Arnaud R, Nanci A. Identification of secreted and membrane proteins in the rat incisor enamel organ using a signal-trap screening approach. Eur J Oral Sci 2006;114:139-46.

Moffatt P, Smith CE, St Arnaud R, Nanci A. Characterization of Apin, a secreted protein highly expressed in tooth-associated epithelia. J Cell Biochem 2008;103:941-56.
Moradian-Oldak J, Bouropoulos N, Wang L, Gharakhanian N. Analysis of self-assembly and apatite binding properties of amelogenin proteins lacking the hydrophilic C-terminal. Matrix Biol 2002;21:197205.

Murshed M, Harmey D, Millan JL, McKee MD, Karsenty G. Unique coexpression in osteoblasts of broadly expressed genes accounts for the spatial restriction of ECM mineralization to bone. Genes Dev 2005; 19:1093-104.

Nanci A. Content and distribution of noncollagenous matrix proteins in bone and cementum: Relationship to speed of formation and collagen packing density. J Struct Biol 1999;126:256-69.

Nanci A, Bendayan M, Bringas PJr, Slavkin HC. High resolution immunocytochemical localization of enamel proteins in mouse ameloblasts in situ and in culture. INSERM 1984a; 125: 333-40.

Nanci A, Bendayan M, Slavkin HC. Distribution of enamel proteins antigens during mouse incisor amelogenesis as revealed by high resolution immunocytochemistry. In: Fearnhead RW, Suga S, editors. Tooth Enamel IV. Amsterdam: Elsevier Science Publishers B.V.; 1984b. p. 141-5.

Nanci A, Bendayan M, Slavkin HC. Enamel protein biosynthesis and secretion in mouse incisor secretory ameloblasts as revealed by high-resolution immunocytochemistry. J Histochem Cytochem 1985:33:1153-60.

Nanci A, Fortin M, Ghitescu DL. Endocytotic functions of ameloblasts and odontoblasts: Immunocytochemical and tracer studies on the uptake of plasma proteins. Anat Rec 1996a;245:219-34.

Nanci A, Hashimoto J, Zalzal S, Smith CE. Transient accumulation of proteins at interrod and rod enamel growth sites. Adv Dent Res 1996b;10:135-49.

Nanci A, McKee MD. The bone-biomaterial interface contains similar components as naturally-occurring cement lines in bone. In: Jouffrey B, Colliex C, Hernandez-Verdun D, Schrevel J, Thomas D, editors. Electron Microscopy 1994 - Applications in Biological Sciences (Volume 3B). Les Ulis Cedex A, France: Les éditions de physique; 1994. p. 885-6.

Nanci A, Slavkin HC, Smith CE. Immunocytochemical and radioautographic evidence for secretion and intracellular degradation of enamel proteins by ameloblasts during the maturation stage of amelogenesis in rat incisors. Anat Rec 1987a;217:107-23.

Nanci A, Warshawsky $\mathrm{H}$. Characterization of putative secretory sites on ameloblasts of the rat incisor. Am J Anat 1984;171:163-89.

Nanci A, Wazen RM, Zalzal S, Fortin M, Goldberg HA, Hunter GK, Ghitescu DL. A tracer study with systemically and locally administered dinitrophenylated osteopontin. J Histochem Cytochem 2004; 52:1591-600.

Nanci A, Zalzal S, Fortin M, Mangano C, Goldberg HA. Incorporation of circulating bone matrix proteins by implanted hydroxyapatite and at bone surfaces: Implications for cement line formation and structuring of biomaterials. In: Davies JE, editor. Bone Engineering. Toronto: em2; 2000. p. 305-11.

Nanci A, Zalzal S, Kan FWK. High-resolution scanning electron microscopy of rat incisor ameloblasts. Scan Microsc 1993a; 7: 16575.

Nanci A, Zalzal S, Kogaya Y. Cytochemical characterization of basement membranes in the enamel organ of the rat incisor. Histochemistry 1993b; 99: 321-31.

Nanci A, Zalzal S, Lavoie P, Kunikata M, Chen W-Y, Krebsbach PH, et al. Comparative immunochemical analyses of the developmental expression and distribution of ameloblastin and amelogenin in rat incisors. J Histochem Cytochem 1998;46:911-34.

Nanci A, Zalzal S, Smith CE. Application of backscattered electron imaging and lectin-gold cytochemistry to visualize the distribution of glycoconjugates in a basal lamina. Scan Microsc 1987b; 1: 196370.

Nanci A, Zalzal S, Smith CE. Routine use of backscattered electron imaging to visualize cytochemical and autoradiographic reactions in semi-thin plastic sections. J Histochem Cytochem 1990;38:403-14.

Oldberg A, Franzen A, Heinegard D. The primary structure of a cellbinding bone sialoprotein. J Biol Chem 1988; 263:19430-2.

Orsini G, Zalzal S, Nanci A. Localized infusion of tunicamycin in rat hemimandibles: alteration of the basal lamina associated with maturation stage ameloblasts. J Histochem Cytochem 2001; 49: 16576.

Riminucci M, Silvestrini G, Bonucci E, Fisher LW, Robey PG, Bianco 
P. The anatomy of bone sialoprotein immunoreactive sites in bone as revealed by combined ultrastructural histochemistry and immunohistochemistry. Calcif Tiss Res 1995; 57: 277-84.

Rittling SR, Matsumoto HN, McKee MD, Nanci A, An X, Novick KE, et al. Mice lacking osteopontin show normal development and bone structure but display altered osteoclast formation in vitro. J Bone Miner Res 1998; 13: 1101-11.

Saito T, Yamauchi M, Abiko Y, Matsuda K, Crenshaw MA. In vitro apatite induction by phosphophoryn immobilized on modified collagen fibrils. J Bone Miner Res 2000; 15: 1615-9.

Saito T, Yamauchi M, Crenshaw MA. Apatite induction by insoluble dentin collagen. J Bone Miner Res 1998; 13: 265-70.

Sire JY, Delgado S, Fromentin D, Girondot M. Amelogenin: lessons from evolution. Arch Oral Biol 2005;50:205-12.

Smith CE. Cellular and chemical events during enamel maturation. Crit Rev Oral Biol Med 1998;9:128-61.

Smith CE, Nanci A. The protein dynamics of amelogenesis. Anat Rec 1996;245:186-207.

Smith CE, Nanci A. Overview of morphological changes in enamel organ cells associated with major events in amelogenesis. Int J Dev Biol 1995; 39: 153-61.

Stubbs JT, III, Mintz KP, Eanes ED, Torchia DA, Fisher LW. Characterization of native and recombinant bone sialoprotein: delineation of the mineral-binding and cell adhesion domains and structural analysis of the RGD domain. J Bone Miner Res 1997;12: 1210-22.

Tye CE, Rattray KR, Warner KJ, Gordon JAR, Sodek J, Hunter GK Goldberg HA. Delineation of the hydroxyapatite-nucleating domains of bone sialoprotein. J Biol Chem 2003;278:7949-55.

Uchida T, Murakami C, Dohi N, Wakida K, Satoda T, Takahashi 0. Synthesis, secretion, degradation and fate of ameloblastin during the matrix formation stage of the rat incisor as shown by immunocyto- chemistry and immunochemistry using region-specific antibodies. $J$ Histochem Cytochem 1997;45:1329-40.

van den Bos T, Speijer D, Bank RA, Bromme D, Everts V. Differences in matrix composition between calvaria and long bone in mice suggest differences in biomechanical properties and resorption Special emphasis on collagen. Bone 2008;43:459-68.

van den Bos T, Bronckers AL, Goldberg HA, Beertsen W. Blood circulation as source for osteopontin in acellular extrinsic fiber cementum and other mineralizing tissues. J Dent Res 1999;78:1688-95.

Vu D-D, Daniel NG, Nanci A. In vivo model for the experimental manipulation of calcified tissues: a surgical approach for accessing the odontogenic organ and associated tissues in the rat incisor. $J$ Histochem Cytochem 1999;47:1-14.

Wazen RM, Moffatt P, Zalzal SF, Daniel NG, Westerman KA, Nanci A. Local gene transfer to calcified tissue cells using prolonged infusion of a lentiviral vector. Gene Ther 2006;13:1595-602.

Wazen RM, Tye CE, Goldberg HA, Hunter GK, Smith CE, Nanci A. In vivo functional analysis of polyglutamic acid domains in recombinant bone sialoprotein. J Histochem Cytochem 2007;55:35-42.

Weiner S. Organization of extracellularly mineralized tissues: A comparative study of biological crystal growth. CRC Crit Rev Biochem 1986;20:365-408.

Wilt FH. Developmental biology meets materials science: Morphogenesis of biomineralized structures. Dev Biol 2005;280: 15-25.

Yin A, Margolis HC, Yao Y, Grogan J, Oppenheim FG. Multi-component adsorption model for pellicle formation: the influence of salivary proteins and non-salivary phospho proteins on the binding of histatin 5 onto hydroxyapatite. Arch Oral Biol 2005;51:102-10.

Zalzal SF, Smith CE, Nanci A. Ameloblastin and amelogenin share a common secretory pathway and are co-secreted during enamel formation. Matrix Biol 2008;27:352-9. 